\title{
Ultrastructural Study of the in Vitro Interaction between Biomphalaria glabrata Hemocytes and Schistosoma mansoni Miracidia
}

\author{
Wolfan Araque/+ , Emilia E Barrios, Pedro Rodríguez*, Víctor S Delgado, Héctor J Finol*
}

Grupo de Enfermedades Infecciosas, Laboratorio de Parásitos Intestinales, Centro BioMolP, Facultad de Ciencias de la Salud, Universidad de Carabobo, Valencia, Estado Carabobo, Venezuela *Centro de Microscopía Electrónica, Facultad de Ciencias, Universidad Central de Venezuela, Caracas, Venezuela

Biomphalaria glabrata and Schistosoma mansoni relationship was studied by light microscopy (LM) and freezefracture replica technique (FFR). We observed very thin cytoplasmic extensions of hemocytes in the LM, which then surround immobilize the miracidia. FFR images showed that the contact site between hemocytes cytoplasmic extensions and the external tegumentary coat involved only superficial layers of miracidia. Numerous vacuoles and filopodia were observed in the hemocyte cytoplasm, the latter binding with those from neighboring cells. In spite of the close interfilopodia contact, no cellular junctions were seen at these sites nor between filopodia-miracidia contact areas. The observed migration of hemocytes and their disposition in layers surrounding the miracidia in vitro correspond to previous studies.

Key words: Biomphalaria glabrata - Schistosoma mansoni - freeze-fracture replica

The blood fluke, Schistosoma mansoni causes schistosomiasis in man and rodents. This disorder is characterized by the presence of $S$. mansoni eggs in the host liver and intestinal tissues. Biomphalaria glabrata, a freshwater planiform mollusc, is the main intermediate host species for S. mansoni (Rey 1992). In the invertebrate host, S. mansoni grows polyembryonically (Van der Knaap \& Loker 1990, Barrios et al. 2001). The cycle starts in water when $S$. mansoni miracidia penetrate soft regions of the mollusc, lose their ciliated epithelium and become sack-like structures, the sporocysts, constituted internally by germinative or reproductive cells (Coelho 1995, Sapp $\&$ Loker 2000). Several studies have associated the main defense line in B. glabrata against S. mansoni infection with humoral and cellular factors (Ottaviani \& Tarugi 1986), especially hemocytes present in the mollusc hemolymph (Sapp \& Loker 2000). B. glabrata hemocytes are capable of binding and destroying the parasite larvae by (1) phagocytosis of the tegument, (2) liberation of cytotoxic components or (3) both mechanisms simultaneously (Adema \& Loker 1997, Hampton et al. 1998). These defense mechanisms have been described for resistent molluscs whereas in susceptible molluses, the hemocytes bind to the parasites in a transitory and inefficient way allowing the successful evolution of the parasite (Vasquez \& Sullivan 2001).

Financial support: Fonacit UCGEI-2000001901, CDCH-UCV 03-10-4169-2000, and CDCH-UC 99014

${ }^{+}$Corresponding author. Fax: +58-241-8673342. E-mail: waraque@uc.edu.ve

Received 7 April 2003

Accepted 8 October 2003
Morphological and ultrastructural methods previously employed for the characterization of vertebrate immune systems (macrophages, lymphocytes, and polymorphonuclears) under normal conditions and parasitic infections were used for identifying mollusc hemocytes (Sminia \& Barendsen 1980, Ottaviani \& Franchini 1988, Abdul-Salam \& Michelson 1980, Barracco et al. 1993). It has been lately suggested that some bacteria toxins are able to induce the re-arranging of Rho superfamily proteins and cytoskeleton alterations (stress fibers) in epithelial cells (Brest et al. 2003). These findings indicate a new perspective for studying the mechanisms mediating the $B$. glabrata hemocyte and $S$. mansoni larval interaction.

The aim of this investigation was to study ultrastructural aspects of the interaction between $B$. glabrata hemocyte and S. mansoni occurring at the cellular membrane level. For this purpose, a useful methodology for the ultrastructural characterization of membrane systems, the freeze-fracture replica technique (FFR) was used.

\section{MATERIALS AND METHODS}

Miracidia - S. mansoni eggs were purified from the liver and gut sections of hamsters (Mesocricetus auratus) 7 weeks after infection. Briefly, dissected organs were enzymatically digested $(0.25 \%$ trypsin and $0.05 \%$ collagenase in $0.15 \mathrm{M} \mathrm{PBS}, \mathrm{pH} 7.2$ ) then eggs were purified by shifting through metallic meshes, decreasing in size from 420 to $44 \mu \mathrm{m}$. Eggs were collected and hatched under sterile conditions, and the resulting miracidia were sedimented at $4^{\circ} \mathrm{C}$ as described by Césari and Alarcón de Noya (1987). All the animals used in this study were sacrificed in accordance to Venezuelan laws for animal care.

Cytoadherence - Hemocytes were obtained from $B$. glabrata between 7 and $10 \mathrm{~mm}$ diameter. Molluscs were externally rinsed with $25 \%$ isopropylic alcohol and then 
washed three times in a solution containing $100 \mu \mathrm{g}$ streptomycin and $100 \mathrm{IU} / \mathrm{ml}$ penicillin for $20 \mathrm{~min}$ each time. After external drying, molluscs were placed in warm water and hemolymph was collected by cephalopodal puncture. In order to induce the binding of the hemocytes on glass, $125 \mu 1$ hemolymph were placed on glass microslides and incubated in an humid chamber at $27^{\circ} \mathrm{C}$ during $2 \mathrm{~h}$.

In vitro interaction assay - Was done by adding 100 miracidia/100 $\mu$ l PBS to each microslide. Samples were incubated for $90 \mathrm{~min}$ at $27^{\circ} \mathrm{C}$, then evaluated, and images were taken using a Nikon E400 light microscope and FFR in an electron transmission microscope.

In vivo assay - Was carried out on snails between 4-5 weeks after infection; they were dissected and the cephalopodal portion was removed. The replicas were obtained from samples fixed in $2 \%$ glutaraldehyde solution in PBS during $30 \mathrm{~min}$. Samples were gently scraped with a wooden stick from the glass coversheets, cryoprotected in $25 \%$ glycerol in PBS, mounted on replica hats and finally, frozen by immersion in undercooled liquid nitrogen. Frozen samples were kept in liquid nitrogen until use. Frozen samples were cryofractured in a JEOL 9010C freezefracture device $\left(1 \times 10^{-6} \mathrm{~Pa},-120^{\circ} \mathrm{C}\right)$, shadowed with $\mathrm{PT} / \mathrm{C}$ and coated with C. Replicas were cleaned in $50 \%$ chlorox overnight at room temperature, rinsed in distilled water, and collected on 400 mesh copper grids. They were observed in a JEOL transmission electron microscope (JEM Mod. 1220) at $120 \mathrm{kV}$.

\section{RESULTS}

The in vitro observation of the early events of miracidiahemocyte interaction showed three relevant aspects: (1) the migration of the hemocytes towards the proximity of the miracidia; (2) the emission of very thin cytoplasmic extensions of hemocytes (Fig. 1), and (3) a confluence of hemocytes on the miracidia which is finally and totally immobilized (Fig. 2). The light microscopic images showed hemocytes close to miracidia, very thin cytoplasmic extensions which completely surround miracidia before finally immobilizing (Fig. 2). By FFR, hemocytes appear to have a cytoplasm with irregular and sinuous contours containing abundant mitochondria and autophagic vacuoles. We also observed numerous intra-cytoplasmic components as well as some binding areas between hemocytes and the hemocyte cytoplasm revealed abundant organelles and cytoplasmic prolongations; some focal contact points were observed between hemocyte cytoplasmic extensions and the external tegumentary layer of the miracidia (Fig. 3).

The in vivo interaction showed a complex structure similar to a cytoplasmic network surrounding the miracidia (Fig. 4). Internal, middle and external layers of the tegumentary miracidia remained intact (Fig. 5).

\section{DISCUSSION}

Hemocytic activity in B. glabrata is stimulated by several factors, such as secretory/excretory products from $S$. mansoni miracidia. The invertebrate host defense response may include migration, super-oxide anions production associated with an encapsulation process or cell-mediated cytotoxicity reactions (Dikkeboom et al. 1988, Adema et al. 1994, Loverde 1998). All of these responses can occur indifferently in both resistant and susceptible molluscs, especially at the beginning of the interaction. It has been demonstrated that the fundamental difference between resistance or susceptibility is the ability of the parasite to inactivate the hemocyte migration towards the miracidia (Van der Knaap \& Loker 1990, Hahn et al. 2001).

Light microscopy indicated that hemocytes migrate towards miracidia, after which very thin cytoplasmic extensions develop around the miracidia and finally the $S$. mansoni larva is completely surrounded. The present observation corresponds to early stages of encapsulation classically observed in infected mollusc tissues (Sapp \& Loker 2000). The observed multilayer hemocyte arrangement around the miracidia corresponds with the encapsulation response in mollusc tissues (Loker \& Bayne 1982). Morphological characteristics of migrating hemocytes seem to indicate that these cells are a subpopulation of type II hemocyte granulocytes (Delgado et al. 2001). The presence of numerous vesicles and RER in those hemocytes surrounding the miracidia could be associated with increased protein synthesis and production of toxic radicals as has been previously described for studies in vitro (Sapp \& Loker 2000). In contrast with ultrastructural changes observed in hemocyte activation processes, the miracidia lost their external ciliated layer, but no changes were evident as regards the internal architecture of larva. This fact can be explained as an insufficient interaction time between hemocyte and miracidia (Coelho 1995). It has been demonstrated that the effectiveness of the parasitic infection process is based on two factors. First, the ability of the parasite to synthesize antigenic determinants similar to those of the mollusc, a process known as molecular mimesis, and secondly, the absorption and incorporation of mollusc agglutinins and hemolymph soluble components to the tegument surface, a process known as antigenic masking (Coelho 1995).

Our results support the hypothesis that hemocytes migrate, independent on their compatibility with larval miracidia and, that migrations towards more compatible larval are less efficient and the interaction hemocyteparasite less effective (Sapp \& Loker 2000, Montesdeoca et al. 2002). We also show that the multilayer cell arrangement around miracidia is consistent with the observed encapsulation response in mollusc tissues (Loker et al. 1982). Electron microscopy has proved to be a successful tool for studying the early stages of hemocytemiracidia interaction. A more complete study, employing B. glabrata hemocytes incompatible with $S$. mansoni simultaneously interacting with $S$. mansoni miracidia in a toxic radical medium should be undertaken.

\section{ACKNOWLEDGMENTS}

To Olga Ojeda, Jennifer Ayala, Lic Viana Pinto, Dr Frances Osborn, Prof. Carmen Rodríguez for technical assistance on english suggestions and to the Grupo de Polímeros at the Universidad Simón Bolívar, Venezuela for the use of the transmission electronic microscopy. 

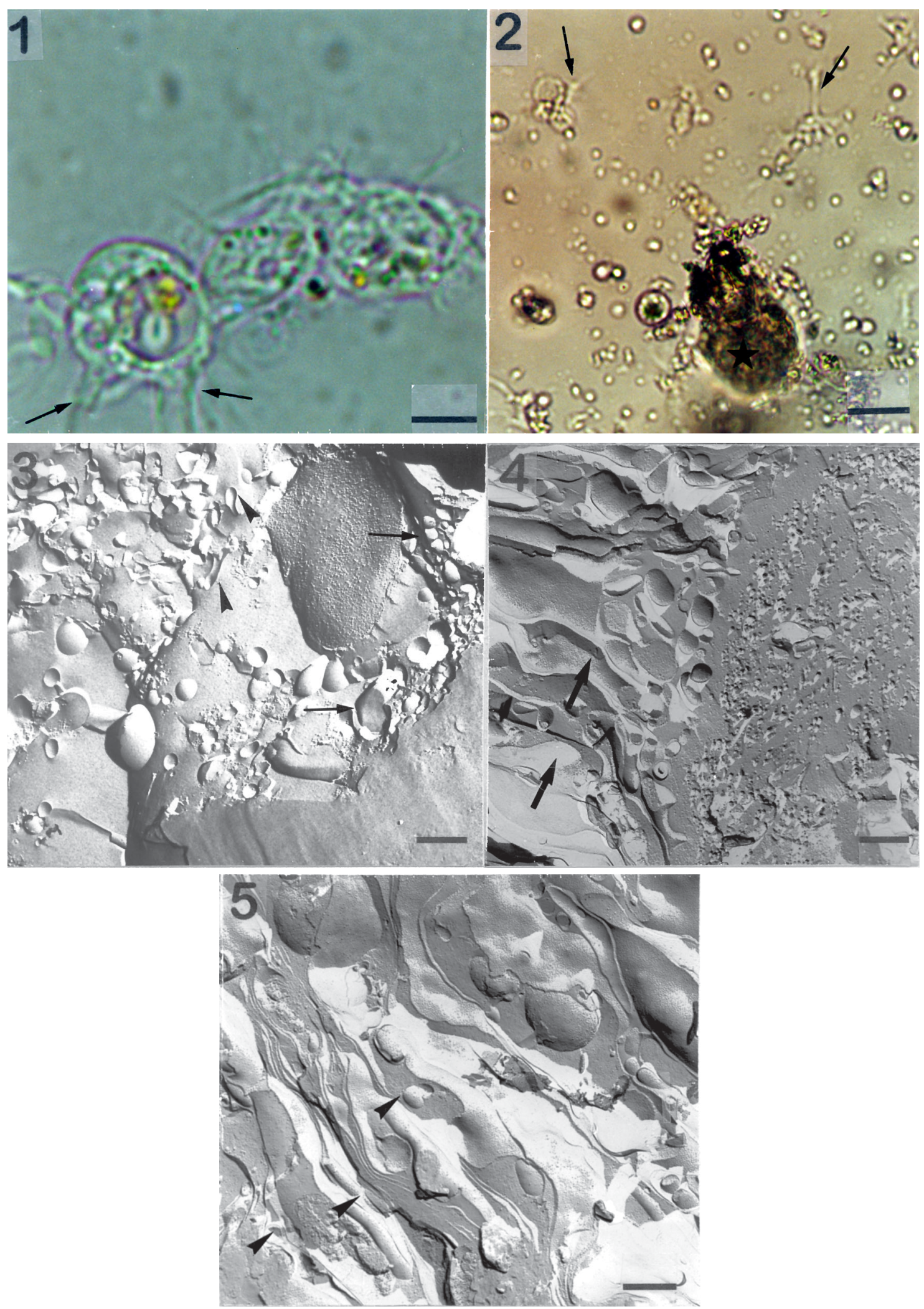

Figs 1, 2: light microscope images of the hemocyte-miracidia interaction. It shows the very thin cytoplasmic prolongations (Fig. 1, arrows) and the confluence of hemocytes (Fig. 2, arrows) around miracidia (Fig. 2, star). Figs 3, 5: freeze-fracture replica images. Irregular and sinuous contours were evident in the hemocyte cytoplasm (Fig. 3, arrowheads), abundant mitochondria, autophagic vacuoles, and numerous intra-cytoplasmic componens (Fig. 3, small arrows). Observe the network-like hemocyte cytoplasm surrounding the miracidia (Fig. 4, large arrows). Layers of miracidia tegument can also be seen (Fig. 5, arrowheads). Bars: Fig. 1: $33 \mu \mathrm{m}$. Figs 2: $3 \mu \mathrm{m}$. Figs 3-5: 500 $\mathrm{nm}$ 


\section{REFERENCES}

Abdul-Salam JM, Michelson EH 1980. Biomphalaria glabrata amoebocytes: effect of Schistosoma mansoni infection on in vitro phagocytosis. $J$ Inverteb Pathol 35: 241-248.

Adema CM, Loker ES. 1997. Specificity and immunobiology of larval digenean-snail associtations. In B Fried, T Graczyk (eds), Advances in Trematode Biology, CRC Press, New York, p. 230-263.

Adema CM, van Deutekom-Mulder EC, van der Knaap WP, Sminia T 1994. Schistosomicidal activities of Lymnaea stagnalis haemocytes: the role of oxygen radicals. $\mathrm{Pa}$ rasitology 109: 479-485.

Barracco MA, Steil AA, Gargioni R 1993. Morphological characterization of the hemocytes of the pulmonate snail Biomphalaria tenagophila. Mem Inst Oswaldo Cruz 88: 73-83.

Barrios EE, Delgado V, Araque W, Márquez M 2001. Schistosoma mansoni transformación de miracidio en su huésped natural y en cultivo. Salus 5: 10-17.

Brest P, Mograbi B, Hofman V, Loubat A, Rossi B, Auberger P, Hofman P 2003. Rho GTPase is activated by cytotoxic necrotizing factor 1 in peripheral blood T lymphocytes: potential cytotoxicity for intestinal epithelial cells. Infect Immun 71: 1161-1169.

Cesari I, Alarcón de Noya B 1987. Esquistosomiasis Mansoni: Diagnóstico y Control. Manual de Campo y de Laboratorio, CEA-IVIC, Venezuela, 319 pp.

Coelho P 1995. Relação molusco/parasita: resistência e susceptibilidade à infecção por Schistosoma mansoni em caramujos do gênero Biomphalaria. In F Carneiro, Tópicos em Malacologia Médica, Fundação Oswaldo Cruz, Rio de Janeiro, 203 pp.

Delgado V, Barrios EE, Bujanda A, Araque W 2001. Surface morphology and characteristics of hemocytes of Biomphalaria glabrata (Pulmonata: Planorbidae) from two geographic sources. Rev Latinoam Microbiol 43: 114-118.

Dikkeboom R, Bayne CJ, van der Knaap W, Tijnagel J 1988. Possible role of reactive forms of oxygen in in vitro killing of Schistosoma mansoni sporocysts by hemocytes of Lymnaea stagnalis. Parasitol Res 75: 148-154.

Hahn UK, Bender RC, Bayne CJ 2001. Killing of Schistosoma mansoni sporocysts by hemocytes from resistant
Biomphalaria glabrata: role of reactive oxygen species. $J$ Parasitol 87: 292-299.

Hampton MB, Kettle AJ, Winterbourn CC 1998. Inside the neutrophil phagosome: oxidants, myeloperoxidase, and bacterial killing. Blood 92: 3007-3017.

Loker ES, Bayne CJ 1982. In vitro encounters between Schistosoma mansoni primary sporocysts and haemolymph components of susceptible and resistant strains of Biomphalaria glabrata. Am J Trop Med Hyg 31: 999-1005.

Loker ES, Bayne CJ, Buckey PM, Kruse KT 1982. Ultrastructure of encapsulation of Schistosoma mansoni mother sporocysts by hemocytes of juveniles of the 10-R2 strain of Biomphalaria glabrata. J Parasitol 68: 84-94.

Loverde PT 1998. Do antioxidants play a role in schistosome host-parasite interactions? Parasitol Today 14: 284-289.

Montesdeoca M, Amano Y, EcheverRia F, Betancourt I, Panchana F, Sotomayor M, Rodríguez J 2002. La respuesta inmunitaria celular del camarón Litopenaeus vannamei al WSSV y su utilidad en el control de la enfermedad en los estanques. El Mundo Acuícola 8: 38-42.

Ottaviani E, Franchini A 1988. Ultrastructural study of haemocytes of the fresh water snail Planorbarius corneus (L) (Gastropoda, Pulmonata). Acta Zool 69: 157-162.

Ottaviani E, Tarugi P 1986. Isolation and characterization of an agglutinin present in the haemolymph of the fresh water snail Planorbarius corneus (L) (Gastropoda, Pulmonata). Comp Biochem Physiol 84: 295-297.

Rey L 1992. Schistosoma mansoni e esquistossomose: o parasito. In Bases da Parasitologia Médica, Guanabanara Koogan, Rio de Janeiro, p. 143.

Sapp KK, Loker ES 2000. Mechanism underlying digeneansnail specificity: role of miracidial attachment and host plasma factors. J Parasitol 86: 1012-1019.

Sminia T, Barendsen L 1980. A comparative morphological and enzyme histochemical study on blood cells of the freshwater snails Lymnaea stagnalis, Biomphalaria glabrata, and Bulinus truncatus. J Morphol 165: 31-39.

Van Der Knaap W, Loker E 1990. Immune mechanisms in trematode-snails interactions. Parasitol Today 6: 175-182.

Vasquez RE, Sullivan JT 2001. Effect of miracidial dose on adoptively transferred resistance to Schistosoma mansoni in the snail intermediate host, Biomphalaria glabrata. $J$ Parasitol 87: 460-462. 